\title{
Diversity and antimicrobial activity of culturable endophytic actinobacteria associated with Acanthaceae plants
}

\author{
Wongsakorn Phongsopitanun ${ }^{\mathrm{a}, \mathrm{b}, *}$, Paranee Sripreechasak ${ }^{\mathrm{c}}$, Kanokorn Rueangsawang ${ }^{\mathrm{a}}$, \\ Rungpech Panyawut ${ }^{\mathrm{a}}$, Pattama Pittayakhajonwut ${ }^{\mathrm{d}}$, Somboon Tanasupawat ${ }^{\mathrm{b}}$ \\ ${ }^{a}$ Department of Biology, Faculty of Science, Ramkhamhaeng University, Bangkok 10240 Thailand \\ b Department of Biochemistry and Microbiology, Faculty of Pharmaceutical Sciences, \\ Chulalongkorn University, Bangkok 10330 Thailand \\ c Department of Biotechnology, Faculty of Science, Burapha University, Chonburi 20131 Thailand \\ d National Center for Genetic Engineering and Biotechnology (BIOTEC), Thailand Science Park, \\ Pathumthani 12120 Thailand
}

*Corresponding author, e-mail: wongsakorn.p@chula.ac.th

Received 20 Oct 2019

Accepted 20 Apr 2020

\begin{abstract}
In this study, a total of 52 endophytic actinobacteria were isolated from 6 species of Acanthaceae plants collected in Thailand. Most actinobacteria were obtained from the root part. Based on 16S rRNA gene analysis and phylogenetic tree, these actinobacteria were classified into 4 families (Nocardiaceae, Micromonosporaceae, Streptosporangiaceae and Streptomycetaceae) and 6 genera including Actinomycetospora (1 isolate), Dactylosporangium (1 isolate), Nocardia (3 isolates), Microbispora (5 isolates), Micromonospora (10 isolates) and Streptomyces (32 isolates). The result of antimicrobial activity screening indicated that 8 isolates, including 1 Actinomycetospora and 7 Streptomyces, exhibited antimicrobial activity against tested microorganisms. In addition, the selected Streptomyces sp. 5R010 showed antagonistic activity against fungal plant pathogens including Fusarium sp., Colletotrichum sp. and Sclerotium sp. Therefore, this study demonstrated that the Acanthaceae plant species harbored the endophytic actinobacteria which can be used as the source of the antimicrobial compound.
\end{abstract}

KEYWORDS: endophytic actinobacteria, antimicrobial activity, Acanthaceae, phytopathogenic fungi

\section{INTRODUCTION}

Microorganisms, especially actinobacteria, are the primary source of the bioactive natural products which is driving drug discovery [1]. In the past century, numerous actinobacteria have been isolated from soil and used as the producer of key drugs such as actinomycin, avermectin, erythromycin, gentamicin, neomycin, platensimycin, streptomycin and vancomycin. Although many drugs are developed from the actinobacteria, the discovery of novel lead compounds has decreased because of the redundancy of the samples. Consequently, it is extremely necessary to investigate the untapped microorganisms to drive natural product research.

Actinobacteria are well known to contain valuable economically important microorganisms for a long time because of their ability to produce a large number of bioactive secondary metabolites [2]. Actinobacteria are one of the major soil microbiota.
However, they are widely distributed in other various environments such as marine sediment, freshwater, insects and plants. In the past decade, the untapped habitats, especially endophytic, have become a promising source of novel actinobacteria [3].

Endophytes are the microorganisms that spend at least parts of their life cycle inside the plant tissues without having a negative impact on the host plants [4]. These microbes, especially actinobacteria, have a massive potential to produce a number of novel compounds that find wide-range application as agrochemicals, antibiotics, immunosuppressants, antiparasitics and anticancer agents [5]. A huge diversity of secondary metabolites of actinobacteria may occur because of the natural adaptation to the environments [6]. Recently, many of novel actinobacteria such as Asanoa endophytica, Phytoactinopolyspora endophytica, Phytohabitans kaempferiae and Streptomyces oryzae have been isolated from various plant species [7-10]. 
Acanthaceae is a family of dicotyledonous flowering plants containing approximately 210 genera and nearly 4000 species. These plants are widely distributed in tropical and subtropical regions [11]. At present, many plant species in this family, for example Andrographis paniculata, Barlelia lupulina, Clinacanthus nurans and Thunbergia laurifolia, have been used for Thai traditional medicines. However, the actinobacteria associated with this plant family are rarely reported. Therefore, the objectives of this study were to study the diversity of endophytic actinobacteria associated with the Acanthaceae plant and to screen the antimicrobial activity of the actinobacterial isolates

\section{MATERIALS AND METHODS}

Plant collections and isolation of actinobacteria

Plant samples were collected and planted in the botanical garden of the Department of Biology, Faculty of Science, Ramkhamhaeng University prior to isolation. In this study, 6 species of plants in the Family Acanthaceae including Andrographis paniculata, Asystasia gangetica, Berleria lupulina, Clinacanthus nutans, Justicia subcoriacea and Ruellia squarrosa were collected.

Actinobacteria were isolated from leaves, stems, and roots of each plant sample. Plant samples were washed to remove soil from the samples. The three-step surface sterilization was used to eliminate the surface microbes. Briefly, a 5-min wash in $3 \% \mathrm{NaOCl}$, followed by a 1-min wash in $95 \%$ ethanol and a final wash with a sterile distilled water 2 times. A $0.5 \mathrm{~g}$ of the surface-sterilized materials was aseptically ground with $5 \mathrm{ml}$ of extraction solution [12]. Then, $0.1 \mathrm{ml}$ of plant suspension was spread on humic acid-vitamin agar [13], starch casein nitrate agar [14] and proline agar [15] supplemented with nalidixic acid $(25 \mathrm{mg} / \mathrm{l})$ and cycloheximide $(50 \mathrm{mg} / \mathrm{l})$ to control the growth of Gramnegative bacteria and fungi, respectively. The plates were incubated at $30^{\circ} \mathrm{C}$ for 14 days. The colonies of actinobacteria were collected and purified on ISP2 medium.

\section{Identification of actinobacteria}

The identification of actinobacteria was performed by $16 \mathrm{~S}$ rRNA gene analysis. The genomic DNA of actinobacteria was extracted from the mycelia grown in yeast-dextrose broth $(1 \mathrm{~g}$ glucose; $1 \mathrm{~g}$ yeast extract; $100 \mathrm{ml}$ water, $\mathrm{pH}$ 7.0-7.2) at $30^{\circ} \mathrm{C}$ for $3-7$ days [16]. The amplification was carried out using standard primers
(5'-GAGTTTGATCCTGGCTCAG-3') and 1530R (5'GTTACCTTGTTACGACTT- $3^{\prime}$ ) with the initial incubation of $3 \mathrm{~min}$ at $94^{\circ} \mathrm{C}$ followed by 30 cycles of $1 \mathrm{~min}$ at $94^{\circ} \mathrm{C}, 1 \mathrm{~min}$ at $50^{\circ} \mathrm{C}$ and $2 \mathrm{~min}$ at $72^{\circ} \mathrm{C}$ and followed by a $3 \mathrm{~min}$ final extension at $72^{\circ} \mathrm{C}[17,18]$. The nucleotide of the PCR product was sequenced using the sequencing service (Macrogen, Korea). The nucleotide sequence was manually analyzed using BioEdit software (Ibis Biosciences). BLAST was determined using the EzbioCloud database [19]. Phylogenetic analysis was constructed using MEGA 7.0 software [20]. The tree topology was evaluated using the bootstrap test [21].

\section{Antimicrobial activity screening}

Antimicrobial activity of actinobacterial isolates was determined using the agar disc diffusion method. Briefly, each actinobacterium was cultured in ISP2 broth $\mathrm{pH} 7.0$ in shaking condition at $180 \mathrm{rpm} 30^{\circ} \mathrm{C}$ for 14 days. Then, one volume (equivalent to culture broth volume) of $95 \%$ ethanol was added and shook at $180 \mathrm{rpm}$ for $1 \mathrm{~h}$ followed by centrifuge at $4500 \mathrm{rpm}$ for $10 \mathrm{~min}$. The supernatant was collected and preserved at $-20^{\circ} \mathrm{C}$. To prepare the tested disc, the sterile paper disc was dipped into each broth library and air-dried in the biosafety cabinet. The sterile ISP2 broth added with one volume of ethanol was used as the negative control.

Six microorganisms including 3 Gram-positive bacteria: Staphylococcus aureus, Bacillus subtilis and Kocuria rhizophila, and 2 Gram-negative bacteria: Escherichia coli and Pseudomonas aeruginosa, and a yeast, Candida albicans, were used as the tested microorganisms. The tested bacteria and yeast were activated on Mueller-Hinton agar (MHA) and sabouraud dextrose agar (SDA) for $27 \mathrm{~h}$ at $37^{\circ} \mathrm{C}$ and $30^{\circ} \mathrm{C}$, respectively. To prepare a microbial suspension, the turbidity of each tested microorganism in normal saline solution was adjusted to 0.5 McFarland standards. Then, the tested bacteria and yeast were swabbed on the surface of MHA and SDA, respectively. The prepared paper disc was put on the surface of media swabbed with the tested microorganisms and incubated for $24 \mathrm{~h}$ at $37^{\circ} \mathrm{C}$ and $30^{\circ} \mathrm{C}$ for bacteria and yeast, respectively. The inhibition zone was observed and documented.

\section{Antagonistic activity against phytopathogenic fungi of the selected strain}

The co-cultivation method was used to determine the antagonistic activity of the selected actinobacteria against 6 phytopathogenic fungi including Colletotrichum gloeosporioides, Colletotrichum sp., 

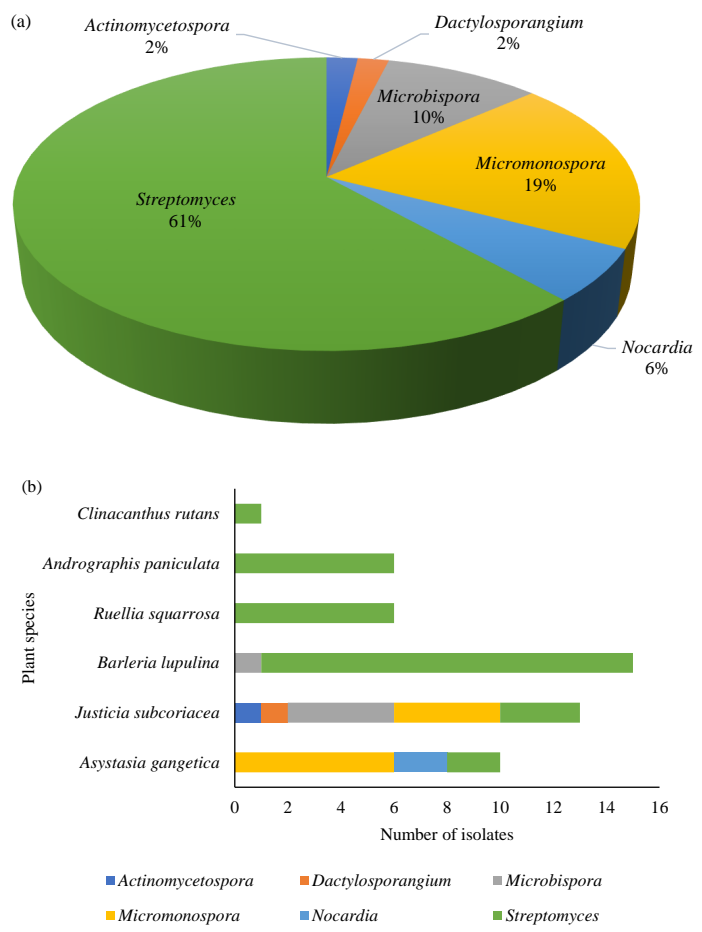

Fig. 1 Diversity of actinobacteria isolated from Acanthaceae plant species. (a) Pie chart represented the percentage of actinobacterial genera within the total number of isolates. (b) The number of actinobacteria isolated from different plant species.

Curvularia oryzae, Fusarium sp., Lasiodiplodia theobromae and Sclerotium sp.

The selected actinobacterium was cultured on one side of the ISP2 agar plate and incubated at $30^{\circ} \mathrm{C}$ for 7 days. Then, the 7-day-old of the tested phytopathogenic fungi grown on SDA agar were cut by the cork borer (6 $\mathrm{mm}$ in diameter) and transferred to the opposite of the prepared actinobacterium plate and incubated at $30^{\circ} \mathrm{C}$ for $7-$ 10 days. The inhibition zone around the actinobacterial colony indicated fungal inhibition. The fungi grown on ISP2 agar without actinobacteria were used as the growth control of the fungi.

\section{RESULTS AND DISCUSSION}

\section{Diversity of actinobacteria}

In this study, 52 actinobacteria were isolated from leaves, stems and roots of 6 species of Acanthaceae plants. In this number, 49 isolates were obtained from roots, followed by 2 and 1 isolate obtained from leaves and stem, respectively. The results of this study are similar to the previous studies showing that nearly all the plants harbor endophytes [22]. Janso and Carter [23] discussed that actinobacteria could be isolated from every tissue type of samples; however, root and bark had the highest isolate-to-sample ratio.

On the basis of BLAST result and phylogenetic tree analysis, actinobacteria obtained in this study were identified and categorized into 4 families (Nocardiaceae, Micromonosporaceae, Streptosporangiaceae and Streptomycetaceae) and 6 genera including Actinomycetospora (1 isolate), Dactylosporangium (1 isolate), Nocardia (3 isolates), Microbispora (5 isolates), Micromonospora (10 isolates) and Streptomyces (32 isolates) (Figs. 1 and 2, Table 1). Based on this study, the most abundant genus found in Acanthaceae plants were Streptomyces (61\%) followed by Micromonospora (19\%) and Microbispora (10\%) (Fig. 1). The pattern of the diversity of culturable actinobacteria of this study, of which Streptomyces are the predominant species, is similar to the previous report [24]. In 2012, Kim et al [25] isolated 61 endophytic actinobacteria, comprising 15 genera including Streptomyces, Micromonospora, Rhodococcus, Microbispora, Micrococcus, Microbacterium, Streptacidiphilus, Arthrobacter, Dietzia, Kitasatospora, Herbiconiux, Mycobacterium, Nocardia, Rathayibacter and Tsukamurella, from the native herbaceous plant species of Korea. In that study, they found that members of the genus Streptomyces comprised $45.9 \%$ of the total isolates and were followed by Micromonospora (18.8\%). In the study of Janso and Carter [23], 123 isolates of endophytic actinobacteria, including 17 genera, were isolated from the tropical native plants in Papus New Guinea and Mborokua Island, Solomon Island. The community of endophytic actinobacteria may vary according to the host plant. Jiang et al [26] isolated 101 endophytic actinobacteria from 5 different mangrove plants including Avicennia marina, Aegiceras corniculatum, Kandelia obovota, Bruguiera gymnorrhiza and Thespesia populnea. Based on $16 \mathrm{~S}$ rRNA gene, these actinobacteria were distributed in 15 families and 28 genera including Actinoplanes, Agrococcus, Amnibacterium, Brachybacterium, Brevibacterium, Citricoccus, Curtobacterium, Dermacoccus, Glutamicibacter, Gordonia, Isoptericola, Janibacter, Kineococcus, Kocuria, Kytococcus, Leucobacter, Marmoricola, Micrococcus, Microbacterium, Micromonospora, Mycobacterium, Nocardioides, Nocardia, Nocardiopsis, Pseudokineococcus, Sanguibacter, Streptomyces and Verrucosispora. In addition, Widiantini and Franco [27] reported that the dominant 


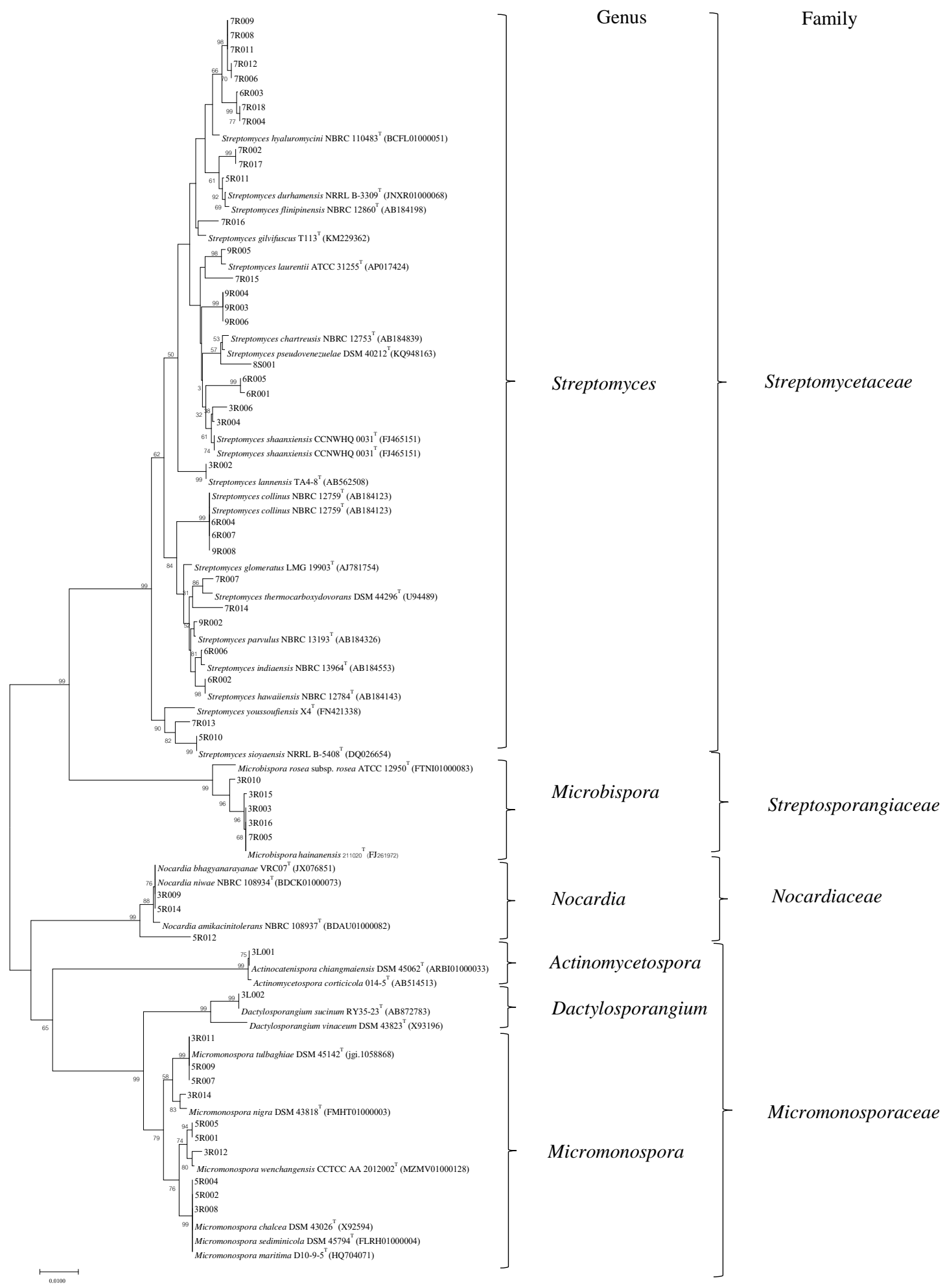

Fig. 2 Neighbor-Joining phylogenetic tree based on 16S rRNA gene of the actinobacterial isolates and closely related actinobacterial type strains shown that the isolates were clustered within 4 families and 6 genera. Numbers at the nodes indicate bootstrap values based on 1000 replicates. 
Table 1 Closest BLASTN matches for the 16S rDNA sequence and antimicrobial activity of the actinobacterial isolates.

\begin{tabular}{|c|c|c|c|c|c|c|c|c|c|c|c|c|}
\hline \multirow{2}{*}{ Plant host } & \multirow{2}{*}{$\begin{array}{l}\text { Plant } \\
\text { material }\end{array}$} & \multirow{2}{*}{$\begin{array}{c}\text { Isolation } \\
\text { no. }\end{array}$} & \multirow{2}{*}{$\begin{array}{c}\text { Accession } \\
\text { no. }\end{array}$} & \multicolumn{2}{|l|}{ BLAST match result } & \multirow{2}{*}{$\begin{array}{l}\text { Isolation } \\
\text { media }\end{array}$} & \multicolumn{6}{|c|}{ Inhibition zone $(\mathrm{mm})$} \\
\hline & & & & Closest species & Similarity \% & & $\mathrm{K}$ & $\mathrm{B}$ & S & $\mathrm{P}$ & E & $\bar{C}$ \\
\hline \multirow{10}{*}{$\begin{array}{l}\text { Asystasia } \\
\text { gangetica }\end{array}$} & \multirow{10}{*}{ Root } & 5R001 & LC497879 & M. chokoriensis DSM $45160^{\mathrm{T}}$ & 99.51 & SCN & - & - & - & - & - & - \\
\hline & & 5R002 & LC497878 & M. maritima D10-9-5 $5^{\mathrm{T}}$ & 100 & SCN & - & - & - & - & - & - \\
\hline & & 5R004 & LC497877 & M. maritima D10-9-5 $5^{\mathrm{T}}$ & 99.79 & SCN & - & - & - & - & - & - \\
\hline & & $5 \mathrm{R} 005$ & LC497876 & M. chokoriensis DSM $45160^{\mathrm{T}}$ & 99.51 & SCN & - & - & - & - & - & - \\
\hline & & 5R007 & LC497873 & M. tulbaghiae DSM $45142^{\mathrm{T}}$ & 100 & SCN & - & - & - & - & - & - \\
\hline & & 5R009 & LC497875 & M. tulbaghiae DSM $45142^{\mathrm{T}}$ & 100 & Proline & - & - & - & - & - & - \\
\hline & & $5 \mathrm{R} 010$ & LC500018 & S. sioyaensis NRRL-B5408 ${ }^{\mathrm{T}}$ & 99.72 & $\mathrm{HV}$ & - & - & - & - & - & 16 \\
\hline & & 5R011 & LC497872 & S. durhamensis NRRL-B3309 & 99.41 & HV & 26 & 15 & 17 & - & - & - \\
\hline & & 5R012 & LC497874 & N. xishanensis NBRC $101358^{\mathrm{T}}$ & 99.93 & HV & - & - & - & - & - & - \\
\hline & & $5 R 014$ & LC497871 & N. bhagyanarayanae $\mathrm{VRC} 7^{\mathrm{T}}$ & 98.68 & SCN & - & - & - & - & - & - \\
\hline \multirow{14}{*}{$\begin{array}{l}\text { Justicia } \\
\text { subcoriacea }\end{array}$} & \multirow{12}{*}{ Root } & 3R002 & LC497888 & S. lannensis $\mathrm{TA} 4-8^{\mathrm{T}}$ & 99.93 & SCN & - & - & - & - & - & - \\
\hline & & 3R003 & LC497882 & M. hainanensis $211020^{\mathrm{T}}$ & 100 & HV & - & - & - & _- & _ & - \\
\hline & & 3R004 & LC497890 & S. shaanxiensis CCNWHQ0031 ${ }^{\mathrm{T}}$ & 99.30 & $\mathrm{HV}$ & 21 & 21 & 27 & & & \\
\hline & & 3R006 & LC497880 & S. cyaneus NRRL B-2296 & 98.91 & $\mathrm{HV}$ & - & - & - & - & - & - \\
\hline & & 3R008 & LC497886 & M. chalcea DSM $43026^{\mathrm{T}}$ & 99.65 & proline & - & - & - & - & _ & - \\
\hline & & 3R009 & LC497889 & N. bhagyanarayanae $\mathrm{VRC} 07^{\mathrm{T}}$ & 99.72 & proline & - & - & _- & _- & - & - \\
\hline & & 3R010 & LC497887 & M. hainanensis $211020^{\mathrm{T}}$ & 99.17 & proline & - & - & - & _- & - & - \\
\hline & & 3R011 & LC497885 & M. tulbaghiae DSM $45142^{\mathrm{T}}$ & 99.44 & SCN & - & - & - & _- & - & - \\
\hline & & 3R012 & LC497891 & M. wenchangensis CCTCCAA $2012002^{\mathrm{T}}$ & T $\quad 99.44$ & SCN & - & - & - & _- & _ & - \\
\hline & & 3R014 & LC497881 & M. nigra DSM $43818^{\mathrm{T}}$ & 98.25 & SCN & - & - & - & _- & - & - \\
\hline & & 3R015 & LC497884 & M. hainanensis $211020^{\mathrm{T}}$ & 99.72 & HV & - & - & - & _- & 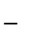 & - \\
\hline & & 3R016 & LC497883 & M. hainanensis $211020^{\mathrm{T}}$ & 99.72 & $\mathrm{HV}$ & - & - & - & - & - & - \\
\hline & \multirow{2}{*}{ Leaf } & 3L001 & LC497892 & Actinomycetospora corticicola $014-5^{\mathrm{T}}$ & 99.62 & Proline & 22 & 19 & 18 & - & - & - \\
\hline & & 3L002 & LC497920 & Dactylosporangium sucinum RY35-23 ${ }^{\mathrm{T}}$ & 99.58 & Proline & - & - & - & - & - & - \\
\hline \multirow{15}{*}{$\begin{array}{l}\text { Barleria } \\
\text { lupulina }\end{array}$} & \multirow{15}{*}{ Root } & 7R002 & LC497919 & S. shenzhenensis $172115^{\mathrm{T}}$ & 99.38 & $\mathrm{HV}$ & - & - & - & - & - & - \\
\hline & & 7R004 & LC497918 & S. shenzhenensis $172115^{\mathrm{T}}$ & 99.65 & Proline & - & - & - & - & - & - \\
\hline & & 7R005 & LC497917 & M. hainanensis $211020^{\mathrm{T}}$ & 99.86 & Proline & - & - & - & - & - & - \\
\hline & & 7R006 & LC497916 & S. graminisoli JR-19 ${ }^{\mathrm{T}}$ & 99.93 & HV & - & - & - & - & - & - \\
\hline & & 7R007 & LC497908 & S. chiangmaiensis $\mathrm{T} 4 \mathrm{~A}-1^{\mathrm{T}}$ & 98.75 & HV & - & - & - & - & - & - \\
\hline & & 7R008 & LC497915 & S. graminisoli JR-19T & 99.51 & HV & - & - & - & - & - & - \\
\hline & & 7R009 & LC497914 & S. graminisoli JR-19 & 99.86 & $\mathrm{HV}$ & - & - & - & - & - & - \\
\hline & & 7R011 & LC497913 & S. graminisoli JR-19 & 99.86 & starch & - & - & - & - & - & - \\
\hline & & 7R012 & LC497912 & S. graminisoli JR- $19^{\mathrm{T}}$ & 99.79 & proline & - & - & - & - & - & - \\
\hline & & 7R013 & LC497911 & S. lilacinus NRRL $1968^{\mathrm{T}}$ & 99.21 & proline & 15 & - & - & - & - & - \\
\hline & & 7R014 & LC497910 & S. lusitanus NBRC $13464^{\mathrm{T}}$ & 99.65 & HV & - & - & - & - & - & - \\
\hline & & 7R015 & LC497906 & S. neopeptinius KNF $2047^{\mathrm{T}}$ & 98.64 & HV & - & - & - & - & - & - \\
\hline & & 7R016 & LC497907 & S. gilvifuscus KM229362 & 98.21 & $\mathrm{HV}$ & - & - & - & - & - & - \\
\hline & & 7R017 & LC500017 & S. shenzhenensis $172115^{\mathrm{T}}$ & 99.45 & HV & - & - & - & - & - & - \\
\hline & & 7R018 & LC497909 & S. shenzhenensis $172115^{\mathrm{T}}$ & 99.58 & $\mathrm{HV}$ & - & - & - & - & - & - \\
\hline \multirow{6}{*}{$\begin{array}{l}\text { Ruellia } \\
\text { squarrosa }\end{array}$} & \multirow{6}{*}{ Root } & 9R002 & LC497898 & S. parvulus NBRC $13193^{\mathrm{T}}$ & 99.72 & $\mathrm{HV}$ & - & - & - & - & - & - \\
\hline & & 9R003 & LC497897 & S. chartreusis $\mathrm{NBRC} 12753^{\mathrm{T}}$ & 99.31 & SCN & 9.5 & 8 & 7 & - & 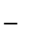 & - \\
\hline & & 9R004 & LC497895 & S. chartreusis $\mathrm{NBRC} 12753^{\mathrm{T}}$ & 99.38 & proline & 8.5 & 8 & - & _- & - & \\
\hline & & 9R005 & LC497896 & S. laurentii ATCC $31255^{\mathrm{T}}$ & 99.31 & $\mathrm{HV}$ & - & - & - & - & - & - \\
\hline & & 9R006 & LC497894 & S. chartreusis $\mathrm{NBRC} 12753^{\mathrm{T}}$ & 99.38 & proline & - & - & - & _- & 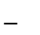 & \\
\hline & & 9R008 & LC497893 & S. collinus NBRC $12759^{\mathrm{T}}$ & 99.93 & $\mathrm{HV}$ & 19 & 12 & 14 & - & - & - \\
\hline & & 6R001 & LC497905 & S. deccanensis DAS-139 ${ }^{\mathrm{T}}$ & 99.78 & $\mathrm{HV}$ & - & - & - & - & - & - \\
\hline & & & LC497904 & S. hawaiiensis NBRC $12784^{\mathrm{T}}$ & 99.72 & $\mathrm{HV}$ & - & - & - & . & - & \\
\hline Andrographis & Bont & 6R003 & LC497903 & S. shenzhenensis $172115^{\mathrm{T}}$ & 99.79 & HV & - & - & - & - & - & - \\
\hline paniculata & Koot & 6R004 & LC497902 & S. collinus NBRC $12759^{\mathrm{T}}$ & 99.93 & $\mathrm{HV}$ & - & - & - & - & 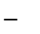 & \\
\hline & & 6R005 & LC497901 & S. deccanensis DAS-139 ${ }^{\mathrm{T}}$ & 99.79 & HV & - & - & - & - & - & - \\
\hline & & 6R006 & LC497900 & S. indiaensis NBRC $13964^{\mathrm{T}}$ & 99.29 & $\mathrm{HV}$ & - & - & - & - & - & - \\
\hline $\begin{array}{l}\text { Clinacanthus } \\
\text { rutans }\end{array}$ & Stem & $8 S 001$ & LC500016 & S. cavourensis NBRC $13026^{\mathrm{T}}$ & 100 & $\mathrm{HV}$ & - & - & - & - & - & - \\
\hline
\end{tabular}

$\mathrm{K}=$ Kocuria rhizophila $; \mathrm{B}=$ Bacillus subtilis $; \mathrm{S}=$ Staphylococcus aureus $; \mathrm{P}=$ Pseudomonas aeruginosa $; \mathrm{E}=$ Escherichia coli; $\mathrm{C}=$ Candida albicans.

endophytic actinobacteria species isolated from rice plants of Australia is Microbispora. The variable of endophytic actinobacterial species in the different plants may depend on factors such as host specificity, stage of the host, type of sample, geographical condition, season, surface sterilant, culture condition and selective media $[28,29]$.

\section{Antimicrobial activity}

In this study, 8 isolates including 1 Actinomycetospora and 7 Streptomyces exhibited antimicrobial activity against tested microorganisms. Most of the active isolates showed antimicrobial activity against Gram-positive bacteria, but no activity was observed 


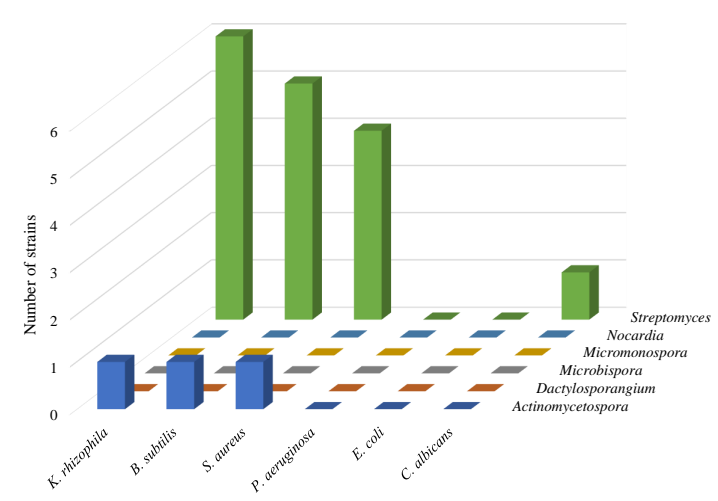

Fig. 3 Antimicrobial activity of the actinobacteria against tested microorganisms.

against Gram-negative bacteria (Fig. 3, Table 1). The antimicrobial activity of endophytic Streptomyces against Gram-positive bacteria has been documented in previous studies. Zhang et al [30] studied antimicrobial activity of 65 endophytic actinobacteria, isolated from Achyranthes bidentata, Paeonia lactiflora, Radix Platycodi and Artemisiae argyi, against penicillin resistant Staphylococcus aureus. They found that 12 strains, the majority of which were Streptomyces spp., showed activity against this pathogen. Although no actinobacteria obtained from this study showed anti-Gramnegative bacterial activity. Mingma et al [31] isolated 317 actinobacteria from root and rhizospheric soils of leguminous plants, and 64 of the isolates (20.2\%) showed antagonistic activity against soybean pathogen Xanthomonas campestris pv. glycine. In addition, 21 endophytic actinobacteria isolated by Jiang et al [26] showed activity against $P$. aeruginosa. This evidence showed that anti-Gramnegative bacteria could be observed in some endophytic actinobacteria.

The production of novel antimicrobial metabolites from endophytic actinobacteria has been documented in the various reports. These include maklamicin, misamycin and diastaphenazine.

Maklamicin, a new spirotetronate-class polyketide isolated from Micromonospora sp. GMKU326 - the endophytic actinobacteria from root nodule of the legume Lupinus angustifolius, showed strong to moderate antimicrobial activity against Grampositive bacteria including Micrococcus luteus, Bacillus subtilis, B. cereus, Staphylococcus aureus and Enterococcus faecalis with MIC values of 0.2, 1.7, 6.5, 13 and $13 \mu \mathrm{g} / \mathrm{ml}$, respectively [32].

Misamycin, a new anthracycline antibiotic, was isolated from the culture broth of endophytic Streptomyces sp. YIM66403. The compound exhibited moderate antibacterial activity against $S$. aureus with MIC value of $64 \mu \mathrm{g} / \mathrm{ml}$. Besides antibacterial activity, it showed cytotoxicity against various human cell lines including human promyelocytic leukemia HL-60, human hepatoma SMMC-7721, non-small cell long cancer A-549, breast cancer MCF-7 and human colorectal carcinoma SW4801 with $\mathrm{IC}_{50}$ values of 15.37, 16.34, 25.98, 20.71 and $9.75 \mu \mathrm{M}$, respectively [33].

Diastaphenazine, a new dimeric phanazine, was isolated from the culture broth of endophytic Streptomyces diastacicus subsp. ardesiacus from sterile tissue of Artemisia annua. The compound showed antimicrobial activity against Staphylococcus aureus ATCC 25923, Escherichia coli ATCC 25922 and Candida albicans ATCC 10231. In addition, it showed weak cytotoxicity against 5 human tumor cell lines including BGC-823, Hela, HCT116, HepG2 and $\mathrm{H} 460$ with $\mathrm{IC}_{50}$ values of 14.9, 28.8, 65.2, 82.5 and $>100 \mu \mathrm{M}$, respectively [34].

In this study, the isolate 5R010, closely related to Streptomyces sioyaensis NRRL-B5408 ${ }^{\mathrm{T}}$, showed antifungal activity against $C$. albicans. This isolate was selected to test the antagonistic activity against phytopathogenic fungi.

\section{Antiphytopathogenic fungi activity}

Based on the co-cultivation method, the strain 5R010 showed antagonistic activity against Fusarium sp., Colletotrichum sp. and Sclerotium sp., but no activity was observed on Colletotrichum gloerosporiodes, Curvularia oryzae and Lasiodiplodia theobromae (Fig. 4). It has been reported in several studies that the endophytic actinobacteria can be used to control plant diseases. Álvarez-Pérez et al [35] used endophytic actinobacteria isolated from the root system of the grapevine plants, Vitis vinifera, to reduce nursery fungal graft infections caused by Diplodia seriata, Dactylonectria macrodidyma, Phaeomoniella chlamydospora and Phaeoacremonium minimum. Taechowisan et al [36] reported that 3 endophytic Streptomyces sp. showed strong inhibition for Colletotrichum musae and 5 were very active against Fusarium oxysporum. The Streptomyces strain CEN6, isolated from Centella asiatica, showed good antagonistic activity against Alternaria brassicicola; the pathogen causes leaves spot of cabbage. The fungal treated by this stain showed abnormal characteristics including swelling and frequent septa [37]. The use of endophytic Streptomyces platensis F-1, isolated from Oryza sativa, as biofumigation to control 


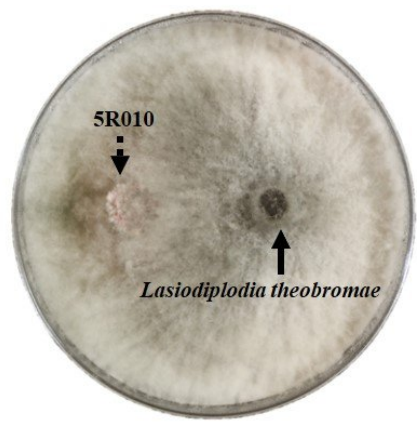

(a)

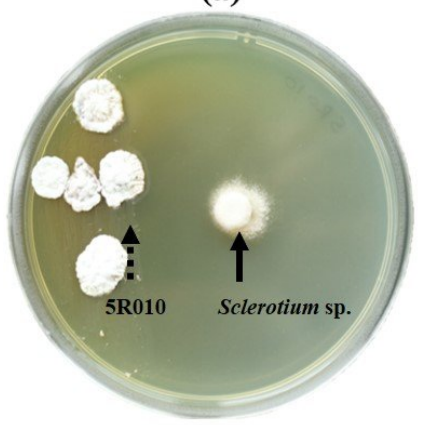

(d)

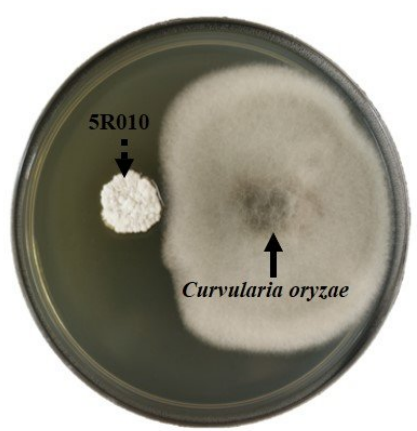

(b)

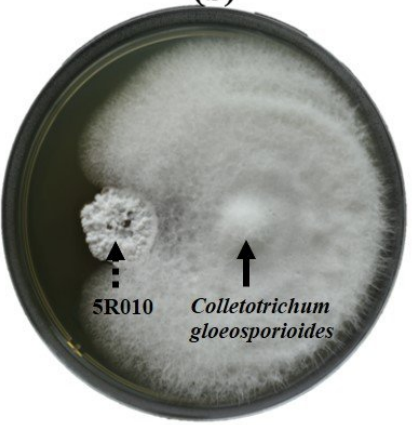

(e)

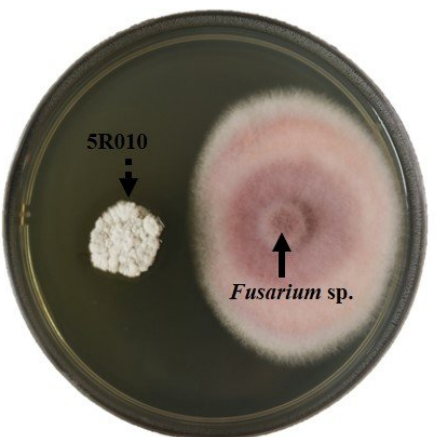

(c)

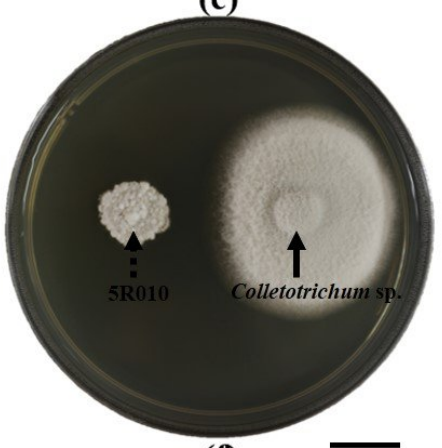

(f)

$\overline{10 \mathrm{~mm}}$

Fig. 4 Antagonistic activity of the isolate 5R010 against phytopathogenic fungi (a) Lasiodiplodia theobromae, (b) Curvularia oryzae, (c) Fusarium sp., (d) Sclerotium sp., (e) Colletotrichum gloeosporioides and (f) Colletotrichum sp. The arrows $\rightarrow$ and $\longrightarrow$ indicate the colony of isolate 5 R010 and fungal pathogens, respectively.

plant fungal disease was reported by Wan et al [38]. The volatile substance produced by the strain F-1 could effectively reduce the incidence and the severity of the disease caused by Botrytis cinerea, Rhizoctonia solani and Sclerotinia sclerotiorum. Besides the application as biocontrol, the novel antifungal compounds such as dehydroxyaquayamycin B and fistupyrone were isolated from endophytic actinobacteria. Dehydroxyaquayamycin B, a new C-glycosylated benz $[\alpha]$ anthraquinone, was isolated from endophytic Streptomyces blastomycetica F4-20. The compound showed fungicidal activity against Valsa mali, Colletotrichum orbiculare and Fusarium graminearum [39]. Fistupyrone, a new microbial compound, isolated from the culture broth of endophytic Streptomyces sp. TP-A0569 can inhibit the in vivo infection of the seedlings of Chinese cabbage by Alternaria brasicicola, the cause of Alternaria leaf spot [40]. The antagonistic activity of the strain 5R010 found in this study revealed that this strain may be used for the fungal biocontrol in the future. In addition, the active compounds produced by this strain should be characterized in further study.
Acknowledgements: This study was supported by the Thailand Research Fund (MRG6180011) to W.P. We thank Asst. Prof. Dr. Narit Thaochan, Department of Pest Management, Faculty of Natural Resources, Prince of Songkla University, Thailand for providing the plant fungal pathogen used in this study. We thank Asst. Prof. Thamasak Yeemin and Dr. Makamas Sutthacheep, Faculty of Science, Ramkhamhaeng University, Thailand for supporting this study with the PCR machine.

Authors' contributions: we declare that the present study was performed by the authors named in this article. W. Phongsopitanun designed the study and performed experiments on isolation, identification of actinobacteria and screening of antimicrobial activity of the actinobacterial isolates; P. Sripreechasak performed experiments on data analysis; K. Rueangsawang and R. Panyawut performed experiments on plant sample collection and identification of the plant species; P. Pittayakhajonwut and S. Tanasupawat gave conceptual advice.

\section{REFERENCES}

1. Matsumoto A, Takahashi Y (2017) Endophytic actinomycetes: promising source of novel bioactive compounds. $J$ Antibiot 70, 514-519. 
2. Berdy J (2005) Bioactive microbial metabolites. $J$ Antibiot 58, 1-26.

3. Berdy J (2012) Thoughts and facts about antibiotics: Where we are now and where we are heading. $J$ Antibiot 65, 385-395.

4. Hardoim PR, Overbeek LSV, Berg G, Pirttila AM, Compant S, Campisano A, Doring M, Sessitsch A (2015) The hidden world within plants: ecological and evolutionary considerations for defining functioning of microbial endophytes. Microbiol Mol Biol Rev 79, 293-320.

5. Gunatilaka AAL (2006) Natural products from plantassociated microorganisms: distribution, structural diversity, bioactivity and implications of their occurrence. J Nat Prod 69, 509-526.

6. Golinska P, Wypij M, Agarkar G, Rathod D, Dahm H, Rai M (2015) Endophytic actinobacteria of medicinal plants: diversity and bioactivity. Antonie Van Leeuwenhoek 108, 267-289.

7. Li L, et al (2015) Phytoactinopolyspora endophytica gen nov., sp. nov., a halotolerant filamentous actinomycete isolated from the roots of Glycyrrhiza uralensis F. Int J Syst Evol Microbiol 65, 2671-2677.

8. Mingma R, Duangmal K, Thamchaipenet A, Trakulnaleamsai S, Matsumoto A, Takahashi Y (2015) Streptomyces oryzae sp. nov., an endophytic actinomycete isolated from stems of rice plant. $J$ Antibiot 68, 368-373.

9. Nienhom N, Chutraku C, Suriyachadkun C, Thawai C (2016) Asanoa endophytica sp. nov., an endophytic actinomycete isolated from the rhizome of Boesenbergia rotunda. Int J Syst Evol Microbiol 66, 1377-1382.

10. Niemhom N, Chutrakul C, Suriyachadkun C, Thawai C (2016) Phytohabitans kaempferiae sp. nov., an endophytic actinomycete isolated from the leaf of Kaempferia larsenii. Int $J$ Syst Evol Microbiol 66, 2917-2922.

11. Christenhusz MJM, Fay MF, Chase MW (2017) Plant of the World, Royal Botanic Gardens, Kew.

12. Innahashi $Y$, Matsumoto A, Danbara H, Omura S, Takahashi Y (2010) Phytohabitans suffuscus gen. nov., sp. nov., an actinomycete of the family $M i$ cromonospora ceae isolated from plant roots. Int $J$ Syst Evol Microbiol 60, 2652-2658.

13. Hayakwa M, Nonomura H (1987) Humic acidvitamin agar, a new medium for selective isolation of soil actinomycetes. J Ferment Technol 65, 501-509.

14. Küster E, Williams ST (1964) Selection of media for isolation of Streptomycetes. Nature 202, 928-929.

15. Inahashi Y, Matsumoto A, Omura S, Takahashi Y (2011) Streptosporangium oxazolinicum sp. nov., a novel endophytic actinomycete producing new antitrypanosomal antibiotics, spoxazomicins. $J$ Antibiot 64, 297-302.

16. Raeder U, Broda P (1985) Rapid preparation of DNA from filamentous fungi. Lett Appl Microbiol 1, 17-20.

17. Lane DJ (1991) 16S/23S rRNA sequencing. In:
Stackebrandt E, Goodfellow M (eds) Nucleic Acid Techniques in Bacterial Systematics, Wiley, Chichester, pp 115-148.

18. Takahashi Y, Matsumoto A, Seino A, Ueno J, Iwai Y, Omura S (2002) Streptomyces avermectinius sp. nov., an avermectin-producing strain. Int J Syst Evol Microbiol 52, 2163-2168.

19. Yoon SH, Ha SM, Kwon S, Lim J, Kim Y, Seo H, Chun $\mathrm{J}$ (2017) Introducing EzBioCloud: a taxonomically united database of 16S rRNA gene sequences and whole-genome assemblies. Int J Syst Evol Microbiol 67, 1613-1617.

20. Kumar S, Stecher G, Tamura K (2016) MEGA7: molecular evolutionary genetics analysis version 7.0 for bigger datasets. Mol Biol Evol 33, 1870-1874.

21. Felsenstein J (1985) Confidence limits on phylogenies: an approach using the bootstrap. Evolution 39, 783-791.

22. Strobel GA, Daisy B (2003) Bioprospecting for microbial endophytes and their natural products. Microbiol Mol Biol Rev 67, 491-502.

23. Janso JE, Carter GT (2010) Biosynthetic potential of phylogenetically unique endophytic actinomycetes from tropical plants. Appl Environ Microbiol 76, 4377-4386.

24. Zhao K, et al (2018) Actinobacteria associated with Chinaberry tree are diverse and show antimicrobial activity. Sci Rep 8, ID 11103.

25. Kim T, Cho S, Han J, Shin YM, Lee HB, Kim SB (2012) Diversity and physiological properties of root endophytic actinobacteria in native herbaceous plants of Korea. $J$ Microbiol 50, 50-57.

26. Jiang Z, et al (2018) Diversity, novelty, and antimicrobial activity of endophytic actinobacteria from mangrove plants in Beilun Estuary National Nature Reserve of Guangxi, China. Front Microbiol 9, ID 868.

27. Widiantini F, Franco CMM (2019) Microbispora dominate diversity of endophytic actinobacteria in Australian rice plants. In: Hodkinson TR, Doohan FM, Saunders MJ, Murphy BR (eds) Endophyte for a Growing World, Cambridge University Press, Cambridge, pp 167-187.

28. Hallmann J (2001) Plant interactions with endophytic bacteria. In: Jeger MJ, Spence NJ (eds) Biotic Interactions in Pant-Pathogen Association, CABI, Wallingford, pp 87-119.

29. Gaiero JR, McCall CA, Thompson KA, Day NJ, Best AS, Dunfield KE (2013) Inside the root microbiome: bacterial root endophytes and plant growth promotion. Am J Bot 100, 1738-1750.

30. Zhang X, Ren K, Zhang L (2013) Screening and preliminary identification of medicinal plants endophytic actinomycetes used for inhibiting penicillinresistant Staphylococcus aureus. Int J Biol 4, 119-124.

31. Mingma R, Pathom-aree W, Trakulnaleamsai S, Thamchaipenet A, Duangmal K (2013) Isolation of rhizospheric and roots endophytic actinomycetes 
from Leguminosae plant and their activities to inhibit soybean pathogen, Xanthomonas campestris pv. glycine. World J Microb Biot 30, 271-280.

32. Igarashi $Y$, Ogura H, Furihata K, Oku N, Indananda C, Thamchaipenet A (2011) Maklamicin, an antibacterial polyketide from an endophytic Micromonospora sp. J Nat Prod 74, 670-674.

33. Li W, Yang X, Yang Y, Zhao L, Xu L, Ding Z (2015) A new anthracycline from endophytic Streptomyces sp. YIM 66403. $J$ Antibiot 68, 216-219.

34. Li Y, et al (2015) Diastaphenazine, a new dimeric phenazine from an endophytic Streptomyces diastaticus subsp. ardesiacus. J Antibiot 68, 210-212.

35. Álvarez-Pérez JM, González-Garcia S, Cobos R, Olego MA, Ibanez A, Díez-Galán A, Garzón-Jimeno E, Coque JJR (2017) Use of endophytic and rhizosphere actinobacteria from grapevine plants to reduce nursery fungal graft infections that lead to young grapevine decline. Appl Environ Microbiol 83, ID e0156417.

36. Taechowisan T, Peberdy JF, Lumyong S (2003) Iso- lation of endophytic actinomycetes from selected plants and their antifungal activity. World $J$ Microb Biot 19, 381-385.

37. Phuakjaiphaeo C, Kunasakdakul K (2015) Isolation and screening for inhibitory activity on Alternaria brassicicola of endophytic actinomycetes from Centella asiatica (L.) Urban. J Agric Technol 11, 903-912.

38. Wan M, Li G, Zhang J, Jiang D, Huang HC (2008) Effect of volatile substances of Streptomyces platensis F-1 on control of plant fungal diseases. Biol Control 46, 552-559.

39. Yan H, Li Y, Zhang XY, Zhou WY, Feng TJ (2015) A new cytotoxic and anti-fungal C-glycosylated benz $[\alpha]$ anthraquinone from the broth of endophytic Streptomyces blastomycetica strain F4-20. J Antibiot 70, 301-303.

40. Igarashi Y, Ogawa M, Saito Y, Saito N, Yoshida R, Kunoh H, Onaka H, Furumai T (2000) Fistupyrone, a novel inhibitor of the infection of Chinese cabbage by Alternaria brassicicola, from Streptomyces sp. TA0569. J Antibiot 53, 1117-1122. 